IRA-International Journal of Technology \& Engineering ISSN 2455-4480; Vol.06, Issue 02 (2017)

Pg. no. 11-23

Institute of Research Advances http://research-advances.org/index.php/IRAJTE

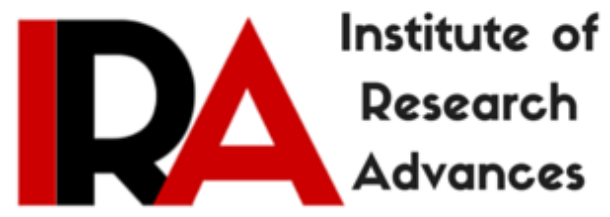

\title{
Logistics Network Design, Shipment Consolidation in a Distribution Centre - Warehouses - Customers Integrated Inventory Model
}

Dr. W. Ritha ${ }^{1} \&$ Mrs. S. Sutha ${ }^{2}$

${ }^{1}$ Assistant Professor of Mathematics, Holy Cross College (Autonomous), Trichy-2, India. ${ }^{2}$ Assistant Professor of Mathematics, Government Arts College, Trichy - 22, India.

Type of Reviewed: Peer Reviewed.

DOI: http://dx.doi.org/10.21013/jte.v6.n2.p1

\section{How to cite this paper:}

Ritha, W., \& Sutha, S. (2017). Logistics Network Design, Shipment Consolidation in a Distribution Centre - Warehouses - Customers Integrated Inventory Model. IRA-International Journal of Technology \& Engineering (ISSN 2455-4480), 6(2), 11-23. doi:http://dx.doi.org/10.21013/jte.v6.n2.p1

(C) Institute of Research Advances

\section{(oc) $\mathrm{EY}$-NC}

This work is licensed under a Creative Commons Attribution-Non Commercial 4.0 International License subject to proper citation to the publication source of the work.

Disclaimer: The scholarly papers as reviewed and published by the Institute of Research Advances (IRA) are the views and opinions of their respective authors and are not the views or opinions of the IRA. The IRA disclaims of any harm or loss caused due to the published content to any party. 


\section{ABSTRACT}

This paper presents a study on multi level customers from three integrated network design and management of inventory to distribute from the various centres. The distribution process is performed through the warehouses situated in different location. Then the assignment will be shipped through the agent of the distribution centres. The main objective of this inventory model is to reduce the transportation and handling costs in the logistics network. This network design to establish the proper shipment model for clear the inventory and to provide an equivalent linear formulation. To prove effectiveness of the model, the strategy for handling the inventory is also proposed to in this study. The results also suggested that the distribution centres with high holding capacities should be arranged and scheduled to deliver their shipments.

Key words: Shipment Consolidation; Logistics Network Design; Inventory Management; Multiple Distribution Centres; Integrated Inventory Model.

\section{Introduction}

In today's competitive environment, companies have outsourced non-value-adding processes and reduced their business activity to core competencies. In many industries, outsourcing ratios have reached $60 \%$ or more (e.g. Muller, 2009), which suggests that managing the supplier base can have a more impact on the cost position of the company. More studies considered the supplier relationship management as an important measure to develop the competitive position of the company (e.g. Dyer, 1996; Saunders, 1997). Production planners should include upstream and downstream companies in their decisions to synchronize material flows and to reduce inventory levels with value creation now taking place in difficult production networks instead of individual companies. If the industries looking after the individual companies, the transportation and handling costs and warehousing cost and so on. Starting with Goyal (1976), a stream of research has emerged in recent years that focuses on the coordination of material movements of semi-finished and finished products. Reducing the total cost of producing and distribution a product in the supply chain increases its competitiveness and produces a cooperation gain that can be delivered among the companies involved.

From the study of the literature reveals that models dealing with the coordination of inventory distribution centres have mainly focused on the sales view of the supply chain, but also taken into consideration the costs that reduce the transportation and handling. In a recent review of joint economic lot size model, Glock ( 2012) pointed only 7 out of 155 papers that considered more than a single supplier, while the other works focused on 1:1 or 1:n relationships. It is obvious that the studying delivery process from a single manufacturer to its customers can help to reduce transportation and inventory carrying costs, and that this may help to improve the cost positions of all companies involved.

However, it is required to study that connection of the manufacturer to its suppliers also need to be studied, and the problem of handling delivery time and quantities in a n:1 = scenario is not necessarily the same companies meet when coordinating deliveries from a producers to multiple distribution centres and to the multiple customers.

The previous research has shown that the timing and size of deliveries from the main distribution centres to the buyers are critical for the cost position of the supply chain (e.g. Glock, 2012 $\&$ Goyal, 2009). The predicament supply chain distributors have to face is that frequent distribution from the suppliers to the buyer reduce the costs related the transaction. Thus, if the cost of delivering products is high, it means directly the affects the costs earned from the distribution centres. Besides transportation cost, the consolidation of shipments also has a positive impact on the environment (Olku, 2012)

One characteristic that has been studied here is that in many practical situations. It is not compulsory to establish a direct connection between each supplier and the buyer. Hence, instead, if the suppliers are located in closer proximity to each other than to the buyer, it can be beneficial to 
consolidate deliveries from manufacturers to the distribution centres. In such a case the buyer receives fewer shipments which results low transportation and handling costs, but increases inventory carrying cost. It is obvious that there is positive in the net benefit of the consolidation shipments.

The aim of this study is to investigate shipment consolidation in multi-distribution centresmulti level buyers integrated inventory model. The next part of this paper is designed as follows. The following two sections give an overview of related works and outline the assumptions and definitions that will be used in the remaining parts of this paper. Sec 4 develops a model of shipment consolidation, and Section 5 contains conclusion of this study and provision o suggestions and for future research.

\section{Literature Review:}

From the works of Goyal (1976) and Banerjee (1986), the cycle of the supply chain production, consumption and delivery cycles are concentrated structure to minimize the total cost . One stream of research for example, studied the impact of alternative shipment policies on the total cost of the supply chain and showed that cost can be reduced in many cases if production quantities are delivered in multiple delivers to the buyer(e.g., Chatterjee \& Ravi, 1991); Goyal \& Nebebe, 2000; Hill. 1997), Hill (1999) and Hill and Omar (2006) expressed that the optimal policy in a singlevendor- single-buyer model is to ship batches that increase in size by a fixed factor, followed by equal-size shipments. To the best of our knowledge, the first attempt to model and solve a problem of this class is given Candas and kutanoglu(2007) Examples for multi-state integrated inventory models are the works of Banerjee and Kim (1995), Khouja(2003), Abdul-jalbar, Gutierrez, and Sicilia(2007), Chung, Wee, and Yang(2008) and Kim and Glock (2013), who added raw material suppliers and distributors in their models.

In the integrated inventory models, the focus was given on single actor on each stage and studied scenarios where a single vendor has to deliver a product to multiple buyers. Several authors implemented a basic cycle time for the buyers in this case to avoid discrete and unequally spaced depletion form the vendor's inventory, which may result in shortages (see.e.g., Bannerjee \& Burton, 1994; Chan \& Kingsman, 2007; Siajadi, Ibrahim, \& Lochert, 2006). Other authors focused on the consequences of vendor-managed inventory or consignment stock on the total cost of the system and showed that the total cost can be reduced if the vendor manages the warehouses at the buyers (e.g., Chen, Lin \& Chen 2010: Darwish \& Odah, 2010: Zavanella \& Zanoni, 2009)

Consideration of multiple suppliers in an integrated inventory model is scarce. Ben-Daya and Al-Nassar (2008) identified one of the first models in this area and studied the case where multiple suppliers deliver to multiple manufacturers, who in turn supply to multiple buyers. The authors considered the case where each stage receives products from a single upstream stage only, wherefore problems that result from overlapping delivery cycles are not considered in this model. A related model is the one of the Jaber and Goyal (2008), who assumed that the suppliers deliver different product components to the buyers, who in turn assembles the components to a final product.

Chen and Sarker(2010) studied a buyer sourcing a product from multiple vendors and assumed that a single truck is used to collect the products from the vendors in a mile-run. A freight cost function, which considers both product weights and travel distances, was used to model freight costs and it was shown that the freight rates favour larger delivery quantities and fewer deliveries. The production lot size, however, was not affected by the cost of delivery. Kim and Goyal (2009) studied two different transportation strategies: in the case of lumpy deliveries, the vendors deliver simultaneously to the buyer, whereas in the case of phased deliveries, the vendors deliver alternately, such that a shipment reaches the buyer exactly when the shipment of the vendor who has delivered before has just been used up.

Glock(2012) studied a system with two vendors and a single buyer and compared the efficiency of six alternative delivery structures. He showed that permitting different lot sizes, shipment frequencies and production intervals at the suppliers reduces the total costs of the system. In 
another paper, Glock (2011) studied a system with multiple heterogeneous suppliers and a single buyer and assumed that the buyer also faces a supplier selection problem. Deliveries of the suppliers were scheduled in such a way that suppliers deliver consecutively to the buyer and that deliveries do not overlap. Glock (2012) studied the case of multiple homogeneous suppliers delivering a product in equal sized shipments to a single buyer. He assumed that the production capacity of a single supplier does not suffice to satisfy demand at the buyer wherefore it is necessary that the delivery cycles of the suppliers overlap. This, in turn, leads to a steady increase in inventory over a cycle, which can be dampened by allocating large order quantities to suppliers that deliver first and smaller quantities to suppliers that deliver last in the sequence. Other works in this stream of research are the ones of Seliaman and Ahmad(2008), Sawik (2009), Leung(2010), Glock (2012) and Glock and Ries (2013).

Location and allocation decisions that take inventory decisions into account are known to be different from those that do not(Baumol \& Wolfe, 1958). Nevertheless, inventory considerations even under deterministic assumptions present nonlinearities that may be quite challenging (Nozick \& Turnquist, 2001). A number of integrated models are studied by Barahona and Jensen (1998), Eriebacher and Meller (2000), Teo, Ou, and Goh(2001) and Miranda and Garrido(2004, 2006) who introduce joint location-inventory models and exploit various heuristics or approximations to solve the resulting nonlinear optimization problems. Nonlinear location models with risk pooling are studied in Shen(2000, 2003) and Shu, Teo, and Shen (2005).

The purpose of this study is to analyse the shipment consolidation in an integrated inventory model. It assumes a buyer who replenishes its inventory from multiple vendors and who has the option to combine several of the vendors in vendors groups. The most related paper is one of Chen and Sarker (2010). However, this work differs from Chen and Sarker (2010) considered the special case of only a single supplier group. In addition, this paper assumes that the supplier delivers to the distribution centre for the individual or single buyers and also for the group of buyers simultaneously.

Finally, Chen and Sarker(2010) studied the case where the production rate of each supplier exceeds the demand rate of the buyer, whereas this work assumes that an individual supplier is not able to satisfy the entire demand at the buyer.

\section{Model Development}

\section{Assumptions and Notations:}

$f_{i} \quad--\quad$ Annual fixed location cost for warehouse $i$.

$C_{i j k}^{1}$-- Unit transportation cost from distribution centre to warehouse $i$ to destination $j$ for part $k$.

$c_{j k m}^{2}$ - Unit transportation cost from destination $j$ to customer $m$ for part $k$.

$h_{i k} \quad--$ Unit holding cost for part $k$ at warehouse $i$.

$t_{j k m}^{1}$-- Transportation time from warehouse $i$ to retailer $j$ for part $k$

$t_{j k m}^{2}$-- Transportation time from retailer $j$ to customer $m$ for part $k$

$d_{j k} \quad$-- Random retailer $j$ demand for part $k$ with mean annual demand

$d_{m k} \quad-$-Random customer $m$ demand for part $k$ with mean annual demand Upper bound on stock level.

$y_{1} \quad$-- Binary location variable.

$X_{i j k}^{1} \quad$-- Long run fraction of retailer $j$ demand for part $k$ served from warehouse $i$. 
$X_{j k m}^{2}$-- Long-run fraction of customer $m$ demand for part $k$ served from retailer $j$.

$S_{i k} \quad-$ Stock level of part $k$ at warehouse $i$.

$w_{k}$-- Time window for part $k$.

$R_{k}$-- Time window for part $k$ from retailers $j$.

A -- Order costs per order for the retailers $j$.

C - Handling costs per shipment for the retailer $j$.

$\mathrm{n}$ - Number of available distribution centres i.

$m_{j}$ - Number Of shipments of distribution centre(DC) $i$ to the retailer in one order cycle, where

$$
1 \leq \mathrm{i} \leq \mathrm{d}
$$

$t_{i} \quad$ - Normalised $I^{s t}$ shipment period from DC to the retailer with respect to $\mathrm{T}$, where

$$
t_{i} \in[0,1] \& \mathrm{t}=\left\{t_{i} \mid 1 \leq i \leq d\right\} .
$$

$\alpha_{i} \quad$ - Normalised shipment interval of DC $i$ with respect to T, Where $\alpha_{i}$ is the fraction of T after which DC $i$ delivers subsequant shipments.

$\delta i_{j} \quad$ - Binary variable that indicates whether vendor $i$ is a member of group $j$, where $\sum_{j=1}^{d} \delta i_{j}=1 \&$ $\sum_{i=1}^{n} \delta i_{j} \geq 1 \forall j$.

$T \quad$ - Order cycle length of the retailer

$Q \quad$ - Order Quantity per cycle, where $\mathrm{Q}=\mathrm{DT}$.

\section{Definitions:}

$q_{i}$-- Order Quantity allocated to distribution centre $i$, where $\mathrm{Q}=\sum_{i=1}^{n} q_{i} \& q_{i}=T p_{i} \sum_{j=1}^{d} \alpha_{j} m_{j} \delta i_{j}$.

$X_{i}$-- Shipment quantity of DC group $i$ with $X_{i}=\alpha_{i} \mathrm{~T} \sum_{i \in \Omega_{\mathrm{i}}} p i$.

$\Omega_{\mathrm{i}}-$ Set of DC in consolidation group $i$, where $1 \leq i \leq d$.

\section{Assumptions:}

- The distribution centre (DC) has an unlimited capacity.

- Warehouse use a continuous review and (s-1, s ) replenish policy with backordering.

- Retailer and Customers demand arrive only at a time according to an Independent Poisson Distribution.

- Parts are shipped directly to corresponding customers without consolidation or bundling.

- Customers are served on at $1^{\text {st }}$ come $1^{\text {st }}$ service basis regardless of their location

- Lateral transhipments are not allowed among warehouses. 
The below figure shows inventory time plots for lot of size for alternative distribution groupings. After the retailer has completed his order, distribution centre starts production and delivers a batch after $t_{1}$ time units. The remaining $2, \ldots \ldots m_{1}$ batches are delivered every $\alpha_{1}$ time units after the first delivery. Since $\mathrm{D}>\sum_{i \in \Omega_{1}} P_{1}$ in case that multiple groups are formed, the first batch of size $x_{1}$ is consumed at the retailer before the second batch from the same distribution group. Thus, the other distribution centre have to deliver at least one batch before the next shipment of the first distribution centre group arrives. However, due to $\sum_{i=1}^{n} P_{1} \geq D$ the second batch of the first distribution centre arrives before the batches that were delivered before have been completely use up. This may result in an increase in inventory over time, as can be seen in the figure. Note that Glock (2012 a) observed a similar behaviour, and denoted stock that is on hand when shipment with ,... of distribution centre arrives as 'Cycle surplus'.

The average inventory at the retailer is computed by referring to the timings of the shipments from the Distribution Centres. A detailed derivation of the average inventory at the retailer, IR. It is obtained by dividing the time weighted inventory at the retailer by the cycle time $T$. The average inventory at the retailer is function of both the time of the 1st shipment of each Distribution Centres, $t$ $\&$ the time between subsequent shipments of each Distribution Centres $\alpha$,

$$
I R(m, T, \delta, t, \alpha)=\frac{T \omega J_{r}}{T}=\frac{D T}{2}-\sum_{j=1}^{d} \sum_{j=1}^{m j}\left(t_{j}+(i-1) \alpha_{j}------(1) .\right.
$$

Deriving the average inventory of Distribution Centres $i$ in group $j$ is straight forward $\&$ it is illustrated in (6).

$$
\begin{aligned}
& I S_{i j}(m, T, \delta, \alpha)=m_{j}\left(\frac{\left(\alpha_{j} T\right) P_{i}\left(\alpha_{j} T\right) \delta_{i j}}{2 T}\right)=m_{j} T\left(\frac{\alpha_{j}^{2} P_{j} \delta_{i j}}{2}\right) \\
& \text { Where } \mathrm{j}=1,2 \ldots . \mathrm{d}, x_{j}=\alpha_{j} T\left(\sum_{i \in \Omega_{j}} P_{i}\right) \\
& \qquad=\alpha_{j} T \sum_{i=1}^{n} P_{i} \delta_{i j} \ldots \ldots \ldots \ldots \ldots . . .(2)
\end{aligned}
$$

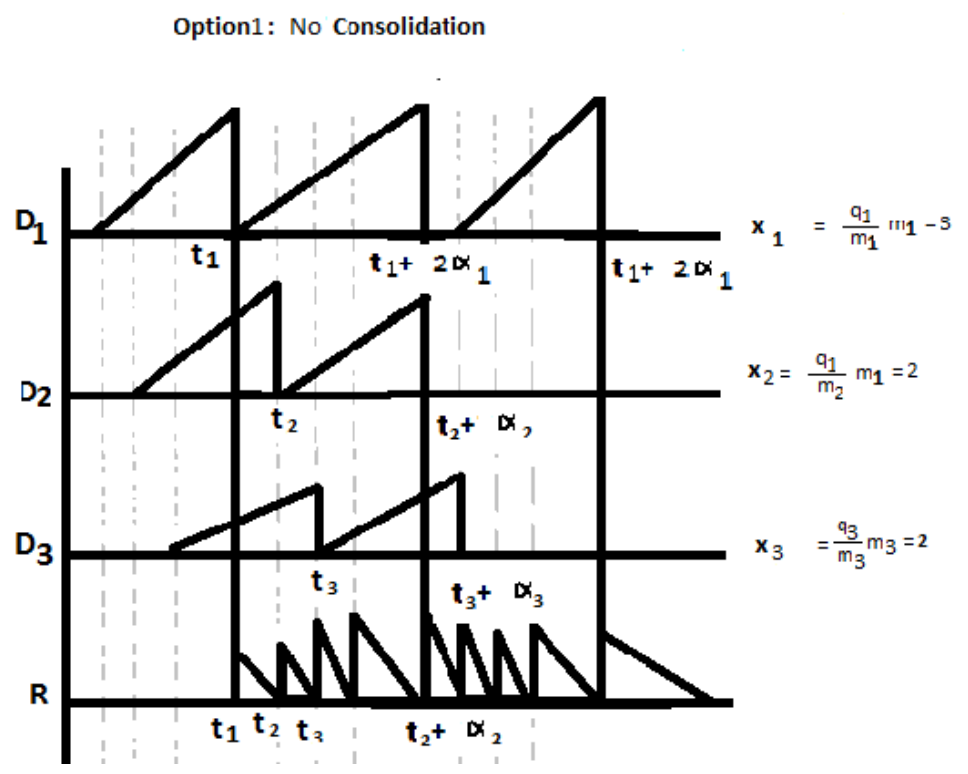



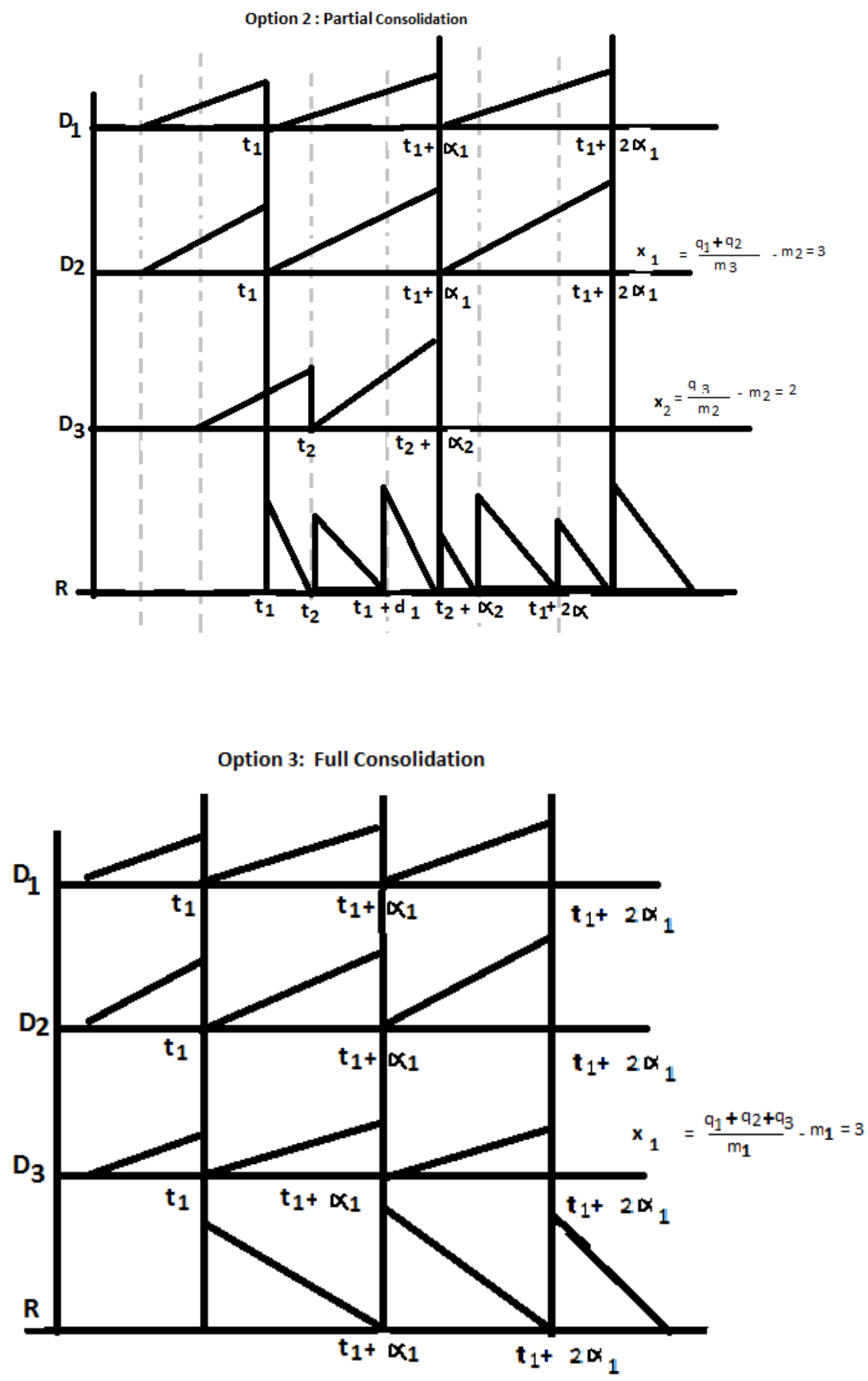

To avoid shortages at the retailer, several constraints for timings between consecutive shipments need to be considered specifically. We formulate two timing constraints for

$$
\begin{aligned}
& \mathrm{t}=\left(t_{1}, t_{2} \ldots \ldots t_{j} \ldots t_{d}\right) \& \alpha=\left\{\alpha_{1}, \alpha_{2} \ldots \alpha_{j} \ldots \alpha_{d}\right\} . \\
& t_{j} \leq \frac{\sum_{k=1}^{j-1} x_{k}}{D T}=\frac{\sum_{k=1}^{j-1} \sum_{i=1}^{n} \alpha_{k} P_{i} \delta_{i k}}{D}, \text { where } j=2,3 \ldots . . \ldots \ldots \ldots \ldots(3) \\
& \alpha_{j}\left(i_{j}\right) \leq \frac{\sum_{k \backslash j}\left(W_{j, k}\left(\left(i_{j}\right)+1\right)\right) \alpha_{k} \sum_{i=1}^{n} P_{i} \delta_{i k}-t_{j} D}{\left(i_{j}-1\right) D-i_{j} \sum_{i=1}^{n} P_{i} \delta_{i j}}------(4)
\end{aligned}
$$


With $w_{j}, k\left(i_{j}\right)=\left(\frac{t_{j}-t_{k}+\left(i_{j}-1\right) \alpha_{j}}{\alpha_{k}}\right)$.

$\operatorname{TRC}(T, m, \delta, t, \alpha, g)=\frac{\left(A+C \sum_{j=1}^{d} m_{j}+\sum_{i=1}^{n} S_{i}\right)}{T}+h^{r} \operatorname{IR}(m, T, \delta, t, \alpha)$

$\sum_{j=1}^{+} \sum_{i=1}^{n} h_{i}^{S} I S_{i j}(m, T, \delta, \alpha)=$

$A+C j=1 d m j+i=1 n S i T+T 2 h r D-j=1 d 2 t j+m j-1 \alpha j m j a j i=1 n p i \delta i j+j=1$ gmjaj $2 i=1$ nhispidij

$T^{*}=\sqrt{\frac{2\left(A+c \sum_{i=1}^{d} m_{j}+\sum_{i=1}^{n} s_{i}\right)}{\left.h^{r}\left(D-\sum_{j=1}^{d}\left(2 t_{j}+\left(m_{j}-1\right) \alpha_{j}\right) m_{j} \alpha_{j} \sum_{t=1}^{n} p_{i} \delta_{i j}\right)\right)+\sum_{j=1}^{d}\left(m_{j} \alpha_{j}^{2} \sum_{i=1}^{n} h_{i}^{s} p_{i} \delta_{i j}\right.}}$

substituting (6) in (5),

$\operatorname{TRC}(m, \delta, t, \alpha, g)=$

$$
\sqrt{2\left(A+c \sum_{j=1}^{d} m_{j}+\sum_{i=1}^{n} S_{i}\right)\left(h^{r}\left(D-\sum_{j=1}^{d}\left(2 t_{j}+\left(m_{j}-1\right) \alpha_{i}\right) m_{j} \alpha_{j} \sum_{i=1}^{n} p_{i} \delta_{i j}\right)+\right.}
$$

Minimize TRC $(m, \delta, t, \alpha, g)$ in (7)

subject to $\left(\left(i_{j}-1\right) D-i_{j} \gamma_{j}\right) \alpha_{j} \leq \sum_{k \backslash_{j}}\left(t_{j}-t_{k}\right) \gamma_{k}-t_{j} D+\left(i_{j}-1\right) \alpha_{j} \sum_{k \backslash_{j}} \gamma_{k}$

where $i_{j}=1,2 \ldots . m_{j}, j=1,2, \ldots \ldots d \& \gamma_{j}=\sum_{i=1}^{n} p_{i} \delta_{i j}$

$m_{j} \alpha_{j} \leq 1$

$\sum_{i=1}^{n} m_{j} \alpha_{j} \sum_{i=1}^{n} p_{i} \delta_{i j}=D$

where $\alpha_{j}>0, t_{j} \geq 0, \delta_{i j} \in\{0,1\}, i=1,2 \ldots . n ; j=1,2 \ldots . d$

\section{Linear Location Inventory Model:}

Let $I_{m}=\{1,2, \ldots \mathrm{m}\}, I_{n}=\{1,2, \ldots \mathrm{n}\} \& I_{p}=\{1,2 \ldots \mathrm{p}\}$ denote the index sets for potential warehouse locations, customers and parts respectively. An annual fixed cost $f_{i}$ is acquired while creating an SPL system, for each open warehouse $i$, holding cost per unit $h_{i k}$, for part $k$ at warehouse $i$, for part $k$ at warehouse $i$ and transportation cost per unit $c_{i j k}$ for part $k$ from warehouse $i$ to customer $j$. The service time, which includes the transportation time from warehouse $i$ to customer $j$ for part $k$ is denoted by $\tau_{i j k}$. For part $k$, the lead time from the distribution centre to 
warehouse $i$ is $t_{i k}$. The demand of customer $j$ for part $k$ is a random variable $d_{i k}$ with Poisson distribution and mean annual demand $d_{i k}$.

The three main sets of decision variables are applied. Variables $x_{i j k} \in\{0,1\}$ represents the long-run fraction of customer $j$ 's demand for part $k$ fulfilled from warehouse $i$. Binary variable $y_{i}$ takes value 1 if warehouse $i$ is open, and 0 otherwise. Integer variable $S_{i k} \in I S_{\max }=$ $\left\{1,2, \ldots \ldots, s_{\max }\right\}$ represents the base stock level of part $k$ at warehouse $i$, where $s_{\max }$ is stocking capacity set a priori on the stock level of part $k$ at a warehouse $i$.

We require that there exists at least one warehouse within the time window $w_{n}$ of each retailer for each part \& $R_{k}$ of each customer for each part, ie.,

$$
\begin{aligned}
& \left.\begin{array}{l}
t_{j k m}^{1} \leq w_{k} \\
t_{j k m}^{2} \leq \overline{w_{k}}
\end{array}\right\} \\
& \forall j \in I_{n} \quad \forall k \in I_{p} \quad \exists i \in I_{m} . \\
& \sum_{i \in I_{m}: t_{j k m}^{1} \leq w_{t}} X_{i j k}^{1}=1,-------(12) \forall j \in I_{n} \quad \forall k \in I_{p} \\
& \sum_{i \in I_{m}: t_{j k m}^{2} \leq \bar{w}_{t}} X_{j k m}^{2}=1,-(11) \forall i \in I_{m} \quad \forall k \in I_{p}
\end{aligned}
$$

Since the demand of retailer $j$ for part $k$ is a random variable with Poisson Distribution $\&$ the demand of customer $m$ for part $\mathrm{k}$ is a random variable with Poisson Distribution, it follows that demand for part $k$ experienced at warehouse $i$ during lead time is Poisson random variable with mean $\lambda_{i k}$

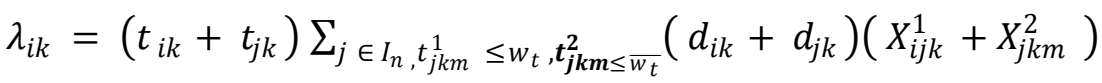

Given that the mean demand $\lambda_{i k}$ and the stock level $S_{i k}$ for part $k$ at warehouse $i$, the achieved service levels for part $k$ at each warehouse is defined as $\beta\left(\lambda_{i k}, S_{i k}\right)=\operatorname{Pr}\left(\widetilde{\lambda_{i k}} \leq S_{i k}-1\right)$.

\section{Part warehouse specific service levels:}

In this case, warehouse $i$ is required to deliver the assigned demand of part $k 100 \alpha_{i k} \%$ of time within the time window $w_{k}$. This is achieved when " the probability that stock probability during lead time is strictly larger than demand" is at least $\alpha_{i k}$. In other words, the stock level $s_{i k}$ of part $k$ at an open warehouse i satisfies

$s_{i k} \leq s_{\max } y_{i}, \forall i \in I_{m}, \forall k \in I_{p}$

$\operatorname{Pr}\left(\overline{\lambda_{i k}} \leq s_{i k}-y_{i}\right) \geq \alpha_{i k}, \forall i \in I_{m}, \forall k \in I_{p}$

Non-linear model for the location inventory problem with part warehouse specific service levels, denoted by SM,

SM:

$\min \sum_{i \epsilon I_{m}} f_{i} y_{i}+\sum_{(i, j, k) \epsilon I_{m} * I_{p} * I_{n}} c_{i j k} d_{j k}\left(X_{i j k}^{1}+X_{j k m}^{2}\right)+\sum_{(i, k) \epsilon I_{m} I_{n}} h_{i k} S_{i k}$

Subject to, $\sum_{i \in I_{m}: t_{j k m}^{1} \leq w_{t}} X_{i j k}^{1}=1, \forall i \in I_{m} \quad \forall k \in I_{p}$

$$
\sum_{i \in I_{m}: t_{j k m}^{2} \leq \overline{w_{t}}} X_{j k m}^{2}=1, \forall j \in I_{m} \quad \forall k \in I_{p}
$$

$0 \leq x_{i j k} \leq y_{i}, \forall i \in I_{m}, \forall j \in I_{n}, \forall k \in I_{p}$ 
$s_{i k} \leq s_{\text {max }} y_{i,}, \forall i \in I_{m}, \forall k \in I_{p}$

$\beta\left(\lambda_{i k} \leq s_{i k}\right)=P_{r}\left(\overline{\lambda_{i k}} \leq s_{i k}-y_{i}\right) \geq \overline{\alpha_{i k}}, \forall i \in I_{m}, \forall k \in I_{p}$ ...(20)

$y_{i} \in\{0,1\}, \forall i \in I_{m}$

$s_{i k} \in\left\{0,1,2 \ldots \ldots \ldots S_{\max }\right\}, \forall i \in I_{m}, \forall k \in I_{p}$

The objective function (17) minimizes the total cost of opening warehouses, transportation and inventory holdings. Under Poisson demand the function $\beta(\lambda, S)$ in $(20)$ is given by $\beta(\lambda, S)=$ $e^{-\lambda} \sum_{r=0}^{s-1} \frac{\lambda^{r}}{r !}, \lambda \in[0, \infty], S \in\{1,2$

where $\beta(0, S)=1 \& \lim _{\lambda \rightarrow \infty} \beta(\lambda, s)=0$. Finally the function is strictly monotonically decreasing with respect to $\lambda \in[0, \infty]$.

Since $\frac{d}{d \lambda} \beta(\lambda, S)=-e^{-\lambda} \frac{\lambda^{S-1}}{(S-1) !}<0 \ldots \ldots$

For any $\alpha \epsilon(0,1), \beta(\lambda, S)=\alpha$ denoted by $\lambda(S, \alpha)$. We replace nonlinear constraints by the following linear equivalents.

$\sum_{s_{\epsilon I S \max }} V_{i k s} \leq y_{i}, \forall i \in I_{m}, \forall k \in I_{p}$

$\lambda_{i k} \leq \sum_{s_{\epsilon I S_{\max }}} \lambda_{s}\left(\alpha_{i k}\right) V_{i k s}, \forall i \in I_{m}, \forall k \in I_{p}$

where $I s_{\max }=\left\{1,2 \ldots . . s_{\max }\right\} \& V_{i k s}$ is a binary variables that takes value 1 if the base stock level part $k$ at warehouse $i$ is otherwise.

Replacing (19) \& (20) by (25) \& (26), we obtain an equivalent reformulation of the nonlinear mixed $I P P S M$ as a mixed $I P P$, denoted by $L M P W$.

$L M P W$ :

$\operatorname{in} \sum_{i \in I_{m}} f_{i} y_{i}+\sum_{(i, j, k) \epsilon I_{m} * I_{p} * I_{n}} c_{i j k} d_{j k} x_{i j k}+\sum_{(i, k) \epsilon I_{m} * I_{p} * I s_{\text {max }}} S h_{i k} V_{i k s}$

subject to $\left.\begin{array}{ll}\sum_{i \in I_{m}: t_{j k m}^{1} \leq w_{t}} X_{i j k}^{1}=1, \forall i \in I_{m} & \forall k \in I_{p} \\ \sum_{i \in I_{m}: t_{j k m}^{2} \leq \overline{w_{t}} X_{j k m}^{2}=1, \forall j \in I_{n}} \quad \forall k \in I_{p}\end{array}\right\}$

$0 \leq x_{i j k} \leq y_{i}, \forall i \in I_{m}, \forall j \in I_{n}, \forall k \in I_{p}$

$\sum_{s \in I s_{\max }} V_{i k s} \leq y_{i}, \forall i \in I_{m}, \forall k \in I_{p}$

$\left.\begin{array}{l}t_{i k} \sum_{i \in I_{m}: t_{j k m}^{1} \leq w_{t}} d_{i k} x_{i j k} \leq \sum_{s \in I s_{\max }} \lambda_{s}\left(\alpha_{i k}\right) V_{i k s} \\ t_{j k} \sum_{j \in I_{n}: t_{j k m}^{2} \leq w_{t}} d_{j k} x_{i j k} \leq \sum_{s \in I s_{\max }} \lambda_{s}\left(\alpha_{j k}\right) V_{i k s}\end{array}\right\}, \forall i \in I_{m}, \forall j \in I_{n}, \forall k \in I_{p}$

$y_{i} \in\{0,1\}, \forall i \in I_{m}$,

$V_{i k s} \in(0,1), \forall i \in I_{m}, \forall k \in I_{p}, \forall S \in I S_{\text {mas }}$ 
In this model, the integer variable $s_{i k}$ are removed and binary variables $V_{i k s}$ are introduced. For any open warehouse $i \&$ any part $k$, there must exist only one \& $s s-t V_{i k s}=1 \&$ for all cloed wareshouse. We must have $V_{i k s}=0$. The stock level warehouse for part $k$ is given by $s_{i k}=$ $\sum_{s \in I S_{\max }} S V_{i k s}$. The values $\lambda f(x)$ are input data of LMPW calculated as the unique solutions of $\beta(\lambda, S)=\alpha$ with respect to $\lambda$ for given $\alpha+\mathrm{s}$ using a Newton method.

\section{Conclusion}

This paper studied the logistics network to design the supply chain towards the buyer through the distribution centres to warehouse and then to final buyer. The distribution centres are spreaded over to all the regions to easy access of the inventory with the intention to satisfy the supply of required or assigned products to the buyer in the supply chain. Whenever requires to supply, this network design reduces the risk of the supplier by the way of delivering the goods as soon as possible from the warehouse where the products were already distributed. To reduce costs and difficulties of inventory to the buyer, it is beneficial to organise the distribution centres in such a way that the buyer receives large shipments at the beginning and towards the end of the delivery cycle and small shipments in between. Further, it was shown that the distribution centres with high production capacities should be deliver in the middle of the delivery cycle, and that the distribution centres with low production capacities should be allocated to a delivery slot early or late in the distribution cycle.

However, this model has several limitations that should be addressed in the future research. First, we did not consider the cost for supplying the products to the distribution centres. Though the distribution process reduces the handling and transportation costs, the costs which spent from the place of producer to the place of distribution centres were not considered. It would also be interest to permit that vendors are part of multiple vendor groups. In this case, the system gains additional flexibility, since vendors with high production capacities can use the transportation equipment of other vendor groups without needing to increase the delivery frequency of the own vendor group.

\section{References}

1. Abdul-Jalbar, B., Gutiérrez, J. M., \& Sicilia, J. (2007). An integrated inventory model for the single-vendor two-buyer problem. International Journal of Production Economics, 108(1-2), 246-258.

2. Banerjee, A. (1986). A joint economic lot size model for purchaser and vendor.

3. Decision Sciences, 17(3), 292-311.

4. Banerjee, A., \& Burton, J. S. (1994). Coordinated vs. independent inventory

5. replenishment policies for a vendor and multiple buyers. International Journalof Production Economics, 35(1-3), 215-222.

6. Banerjee, A., \& Kim, S.-L. (1995). An integrated JIT inventory model. International Journal of Operations and Production Management, 15(9), 237-244.

7. Baumol, W. J., \& Wolfe, P. (1958). A warehouse-location problem. Operations

8. Research, 6, 252-263.

9. Ben-Daya, M., \& Al-Nassar, A. (2008). An integrated inventory production system in a three-layer supply chain. Production Planning and Control, 19(2), 97-104.

10. Candas, M., \& Kutanoglu, E. (2007). Benefits of considering inventory in service parts logistics network design problems with time-based service constraints. IIE Transactions, 39, 159-176.

11. Chan, C. K., \& Kingsman, B. G. (2007). Coordination in a single-vendor multi-buyer supply chain by synchronizing delivery and production cycles. Transportation Research Part E, 43(2), 90-111.

12. Chatterjee, A. K., \& Ravi, R. (1991). Joint economic lot-size model with delivery in subbatches. Operations Research, 28(2), 118-124.

13. Chen, J.-M., Lin, I.-C., \& Chen, H.-L. (2010). Channel coordination under consignment and vendor-managed inventory in a distribution system. Transportation Research Part E, 46, 831843. 
14. Chen, Z. X., \& Sarker, B. R. (2010). Multi-vendor integrated procurement-production system under shared transportation and just-in-time delivery system. Journal of the Operational Research Society, 61, 1654-1666.

15. Chung, S.-L., Wee, H.-M., \& Yang, P.-C. (2008). Optimal policy for a closed-loop supply chain inventory system with remanufacturing. Mathematical and Computer Modelling, 48, 867-881.

16. Erlebacher, S. J., \& Meller, R. D. (2000). The interaction of location and inventory in designing distribution systems. IIE Transactions, 32, 155-166.

17. Glock, C. H. (2012a). Coordination of a production network with a single buyer and multiple vendors. International Journal of Production Economics, 135(2), 771-780.

18. Glock, C. H. (2012b). The joint economic lot size problem: A review. International Journal of Production Economics, 135(2), 671-686.

19. Glock, C. H. (2012c). A comparison of alternative delivery structures in a dual sourcing environment. International Journal of Production Research, 50(11), 3095-3114.

20. Glock, C. H. (2012d). Single sourcing versus dual sourcing under conditions of learning. Computers and Industrial Engineering, 62(1), 318-328.

21. Glock, C. H., \& Ries, J. M. (2013). Reducing lead-time risk through multiple sourcing: The case of stochastic demand and variable lead-time. International Journal of Production Research, 51(1), 43-56.

22. Goyal, S. K. (1976). An integrated inventory model for a single supplier-single customer problem. International Journal of Production Research, 14,107-111.

23. Goyal, S. K., \& Nebebe, F. (2000). Determination of economic production-shipment policy for a single-vendor-single-buyer system. European Journal of Operational Research, 121(1), $175-178$.

24. Hill, R. M. (1997). The single-vendor single-buyer integrated production-inventory model with a generalised policy. European Journal of Operational Research, 97(3), 493-499.

25. Hill, R. M., \& Omar, M. (2006). Another look at the single-vendor single-buyer integrated production-inventory problem. International Journal of Production Research, 44(4), 791-800.

26. Jaber, M. Y., \& Goyal, S. K. (2008). Coordinating a three-level supply chain with multiple suppliers, a vendor and multiple buyers. International Journal of Production Economics, 116(1), 95-103.

27. Kim, T., \& Glock, C. H. (2013). A multi-stage joint economic lot size model with lead time penalty costs. Computers and Industrial Engineering, 66(1), 133-146.

28. Kim, T., \& Goyal, S. K. (2009). A consolidated delivery policy of multiple suppliers for a single buyer. International Journal of Procurement Management, 2(3), 267-287.

29. Nozick, L. K., \& Turnquist, M. A. (2001). Inventory, transportation, service quality and the location of distribution centers. European Journal of Operational Research, 129, 362-371.

30. Nozick, L. K., \& Turnquist, M. A. (2001). A two-echelon inventory allocation and distribution center location analysis. Transportation Research Part E, 37, 421-441.

31. Pan, J. C.-H., \& Yang, J.-S. (2002). A study of an integrated inventory with controllable lead time. International Journal of Production Research, 40(5), 1263-1273.

32. Sarker, B. R., \& Diponegoro, A. (2009). Optimal production plans and shipment schedules in a supply chain with multiple supplier and multiple buyers. European Journal of Operational Research, 194(3), 753-773.

33. Saunders, M. (1997). Strategic purchasing and supply chain management (2nd ed.). Harlow, England: Prentice Hall.

34. Sawik, T. (2009). Monolithic versus hierarchical approach to scheduling in a supply chain. International Journal of Production Research, 47(21), 5881-5910.

35. Seliaman, M. E., \& Ahmad, A. R. (2008). Optimizing inventory decisions in a multistage supply chain under stochastic demands. Applied Mathematics and Computation, 206, 538542.

36. Shen, Z. -J. M. (2000). Efficient algorithms for various supply chain problems. Ph.D. Dissertation, Department of Industrial Engineering and Management Sciences, Northwestern University, Evanston, IL 60208. 
37. Shen, Z.-J. M., \& Daskin, M. S. (2005). Trade-offs between customer service and cost in integrated supply chain design. Manufacturing and Service Operations Management, 7, 188207.

38. Shu, J., Teo, C.-P., \& Shen, Z.-J. M. (2005). Stochastic transportation-inventory

39. network design problem. Operations Research, 53, 48-60.

40. Teo, C.-P., Ou, J., \& Goh, M. (2001). Impact on inventory costs with consolidation of distribution centers. IIE Transactions, 33, 99-110.

41. Ülkü, M. A. (2012). Dare to care: Shipment consolidation reduces not only costs, but also environmental damage. International Journal of Production Economics, 139(2), 438-446.

42. Woo, Y. Y., Hsu, S.-L., \& Wu, S. (2000). Order processing cost reduction in a joint vendorbuyer inventory system via the application of information technology. The Engineering Economist, 45(4), 350-365.

43. Zavanella, L., \& Zanoni, S. (2009). A one-vendor multi-buyer integrated production inventory model: The 'Consignment Stock' case. International Journal of Production Economics, 118, 225-232. 